\title{
Employment characteristics of UK tourism industries in 2008
}

Eddie Smith, Dominic Webber and Sean White

Tourism Intelligence Unit, Office for National Statistics

\section{Summary}

This article uses an analysis of data from the Annual Population Survey to provide estimates of the characteristics of employment in tourism industries in 2008 . The results indicate that employment in these industries is more likely to be part-time, self-employed or temporary than in non-tourism industries.

The data also highlight that the workforce in tourism industries has a younger age profile than in other industries and that there are greater proportions of non-UK born and nonwhite workers in tourism industries. The article includes comparisons of different tourism industries in employment terms and features information at sub-regional geographical level.

\section{Introduction}

In November 2010, a paper examining the supply side of UK tourism industries was published by ONS's Tourism Intelligence Unit ${ }^{1}$ (TIU) (see Smith, Webber and White 2010). It included analysis of output, gross value added (GVA), employment, company size and turnover levels in the industries. The paper also explained how the TIU has matched the internationally agreed definitions of tourism industries to UK Standard Industrial Classifications ${ }^{2}$ (SIC 2003 and SIC 2007). This article uses 2008 data from the Annual Population Survey ${ }^{3}$ (APS) to further explore the characteristics of employment in tourism industries and of those working in them.

The APS is a combined survey of households in the UK. Its purpose is to provide information on key social and socio-economic variables between the ten-yearly censuses, with particular emphasis on providing information relating to small geographical areas. The APS acts as a boost to the Labour Force Survey (LFS) to provide for a more disaggregate analysis of the population. This article includes information for sub-regional geographies and, therefore, the APS has been used in preference to the quarterly LFS. This is because the latter does not provide a large enough sample to give reliable results for small population groups in detailed cross-tabulations of several variables (geographical area and industry, for example). Regular outputs from the APS include 
local area labour market data ${ }^{4}$ and estimates of the UK population by country of birth and nationality ${ }^{5}$. This article uses aggregations of unpublished data that have been accessed via the ONS's Virtual Microdata Laboratory ${ }^{6}$ (VML).

\section{Tourism industries}

The industries for which data have been collected in this article are those that serve tourists, as suggested in international recommendations on tourism statistics ${ }^{7}$ (IRTS) published by Eurostat, UNWTO and OECD in 2008. It should be noted that this article does not provide an estimate of 'Tourism Direct Employment'. Such an estimate would exclude some workers within tourism industries, for example those serving food or beverages to non-tourists, and include some in nontourism industries, such as those that manufacture goods that directly relates to tourism. The TIU is currently considering whether an estimate of Tourism Direct Employment could be included within the 2008 Tourism Satellite Accounts that are due to be released in 2011.

The November 2010 supply side paper highlighted estimates of employment from the APS. These suggested that, in 2008, about 2.36 million people had their main job in one of the tourism industries while just over 180,000 people had a second job within them. Table 1 is a breakdown of main and second employment data into eleven tourism industries and it also includes information about the specific industry classes within the eleven, as well as examples of what is excluded from them.

\section{Table $1 \quad$ Tourism industries and industry classes ${ }^{1}$}

\begin{tabular}{lcc}
\hline \multicolumn{1}{c}{ Estimated employment in main and second jobs, 2008 (thousands) } & Not included \\
\hline $\mathbf{1}$ & $\mathbf{3}$ & Real estate agencies \\
Accommodation for visitors & 250 & 58 \\
Hotels and motels & 27 \\
Other provision of lodgings & 27 \\
Letting own property & 17 \\
Management of real estate on a fee or contract basis & $\mathbf{1 , 0 3 8}$ \\
Camping and caravan sites and youth hostels & 455 \\
Food and beverage serving activities & 271 \\
Restaurants & 151 \\
Public houses and bars & 102 \\
Catering & 36 \\
Take-away food shops & 24 \\
Canteens & \\
Licensed clubs &
\end{tabular}




\begin{tabular}{|c|c|c|c|}
\hline & Estimated employment in main and second jobs, 2008 (thousands) & & Not included \\
\hline \multirow[t]{3}{*}{3} & Railway passenger transport & 49 & \\
\hline & Passenger rail transport, interurban & 49 & Urban and suburban rail transport \\
\hline & & & Freight rail transport \\
\hline \multirow[t]{3}{*}{4} & Road passenger transport & 240 & \\
\hline & Taxis and similar & 194 & Urban and suburban road transport \\
\hline & Other (interurban) passenger land transport & 46 & Freight road transport \\
\hline \multirow[t]{3}{*}{5} & Water passenger transport & 24 & \\
\hline & Sea and coastal passenger water transport & 22 & Freight water transport \\
\hline & Inland passenger water transport & 2 & \\
\hline \multirow[t]{3}{*}{6} & Air passenger transport & 44 & \\
\hline & Scheduled air transport & 31 & Freight air transport \\
\hline & Non-scheduled air transport & 13 & \\
\hline \multirow[t]{3}{*}{7} & Transport equipment rental & 36 & \\
\hline & Car rental & 33 & Rental and leasing of trucks \\
\hline & Other & 2 & and of freight transport \\
\hline \multirow[t]{4}{*}{8} & Travel agencies and other reservation service activities & 126 & \\
\hline & Travel agencies, organisers, guides & 107 & \\
\hline & Other tourist assistance & 11 & \\
\hline & Other & 9 & \\
\hline \multirow[t]{6}{*}{9} & Cultural activities & 267 & \\
\hline & Artistic and literary creation & 149 & Libraries and archives \\
\hline & Other entertainment & 53 & \\
\hline & Museums & 33 & \\
\hline & Arts facilities & 22 & \\
\hline & Other & 9 & \\
\hline \multirow[t]{7}{*}{10} & Sports and recreational activities & 333 & \\
\hline & Operation of sports arena and stadia & 157 & Sports clubs \\
\hline & Gambling and betting & 88 & Fitness facilities \\
\hline & Other recreational activities & 47 & Racehorse owners \\
\hline & Other sporting activities & 24 & \\
\hline & Fairs, amusement parks & 11 & \\
\hline & Other & 6 & \\
\hline \multirow[t]{2}{*}{11} & Country-specific tourism characteristic activities & 11 & \\
\hline & Exhibition, fair and conference organisers & 11 & \\
\hline
\end{tabular}

Source: Annual Population Survey 2008 Note

1. Based on definitions of tourism industries from the UN World Tourism Organisation (UNWTO) 
In the remainder of this article, many of the analyses break down data into four broad tourism industries. These are:

- accommodation for visitors

- food and beverage serving activities

- passenger transport, transport equipment rental and travel agencies etc

- cultural, sport and recreation activities and conference activities etc

These relate, respectively, to the industries labelled 1, 2, 3 to 8 and 9 to 11 in Table 1 .

\section{Tourism occupations}

Within the 2008 APS, occupations were classified using the four-digit 2000 Standard Occupational Classification $^{8}$ (SOC). Some of these relate to specialist areas of work (such as musicians or hotel porters) while others take place within a variety of industries (for example, cleaners and domestics or sales and retail assistants).

\section{Figure $1 \quad$ Main and second job employment in tourism industries: the 30 most prevalent occupations in 2008}

Employment in main and second jobs

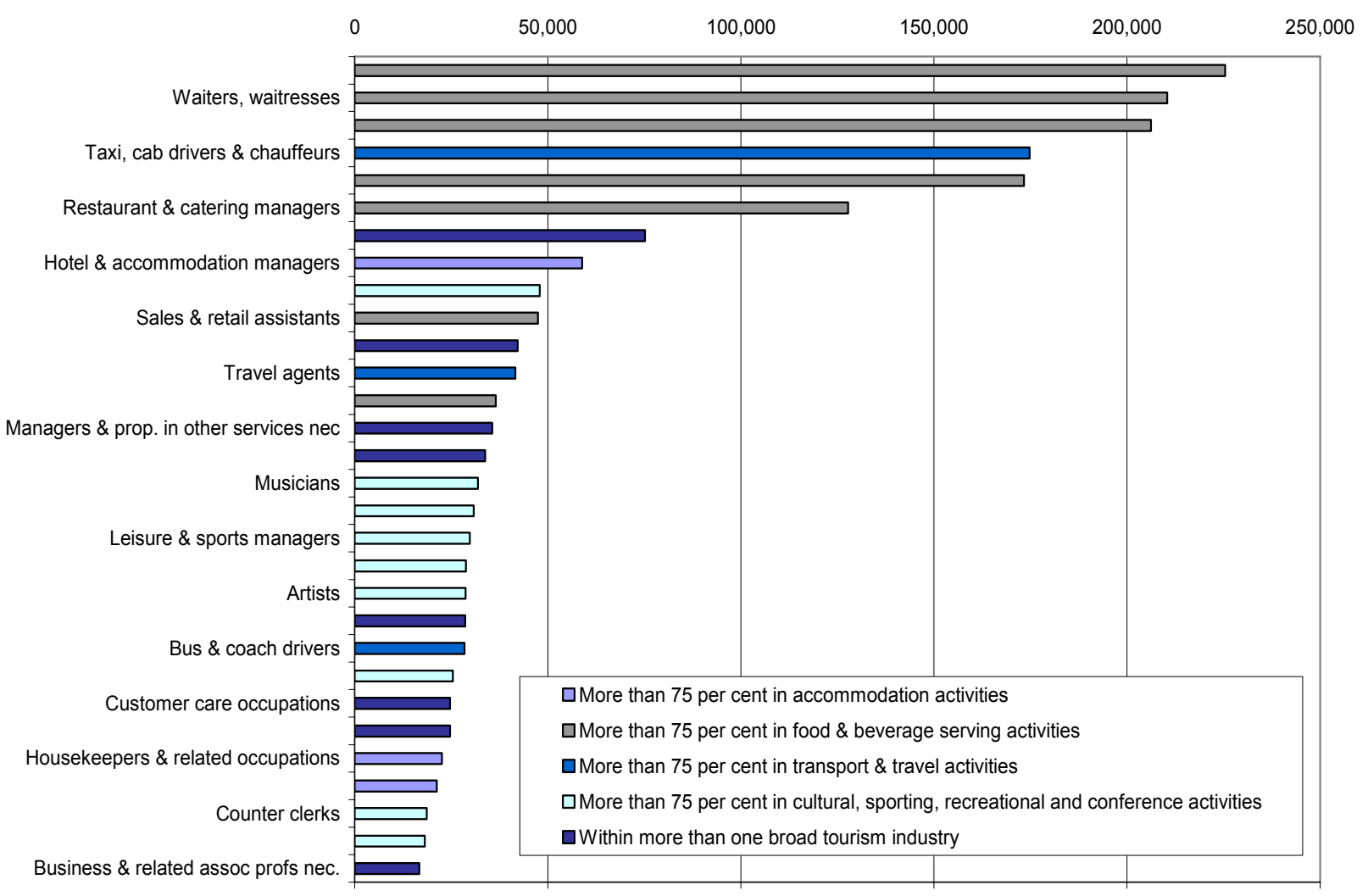

Source: Annual Population Survey 2008

nec $=$ not elsewhere classified 
In 2008, six occupations included about 44 per cent of main and second job employment in tourism industries. Five of these occupations were mainly in food and beverage serving activities with the other almost entirely within passenger transport. Figure 1 illustrates these six occupations and the 24 others with the largest employment in tourism industries in 2008. Together, these 30 occupations had main and second job employment of 1.92 million in tourism but a further 630,000 people employed in tourism industries worked in 258 other occupations.

All occupations in Figure 1 also have workers in non-tourism industries, with many having the majority in these industries. Most notably, only 11 per cent of cleaners and domestics, 4 per cent of sales and retail assistants and 6 per cent of general office assistants or clerks were within tourism industries in 2008 despite these being the $7^{\text {th }}, 10^{\text {th }}$ and $11^{\text {th }}$ most prevalent occupations. Even occupations more obviously relating to tourism industries have large numbers of workers elsewhere. Around 44 per cent of kitchen and catering assistants worked outside tourism industries in 2008 and the same was true of a third of chefs and cooks, about a sixth of bar staff, the same proportion of taxi drivers, cab drivers and chauffeurs and around a tenth of waiters and waitresses.

\section{Characteristics of employment in tourism Industries}

\section{Main and second jobs}

The 2008 estimate of 2.36 million workers with a main job in tourism industries was equivalent to 8.1 per cent of those in the UK with a main job in any industry. The number of second jobs in these industries, however, made up a much larger proportion of second jobs overall, around a sixth, as Table 2 illustrates.

Second jobs are particularly prevalent in cultural, sporting and recreational industries but are also more in evidence in most other tourism industries than in the UK economy as a whole. The exception is passenger transport and travel, where second jobs are relatively rare. The APS includes no measure of third and subsequent jobs which means that it may underestimate employment in industries where these exist. Given the high levels of second jobs in most tourism industries, it is likely that third and subsequent jobs are also more common, suggesting a slight underestimate of the proportion of total employment that is within tourism industries.

In 2008, about 92,000 people who had main jobs in tourism industries had second jobs as well, with about a third of these $(32,000)$ also being in tourism industries. In total, therefore, 2.514 million workers had main and/or second jobs in tourism industries $(32,000$ subtracted from the main and second jobs total in Table 2). 
Table $2 \quad$ Main and second job employment in tourism industries in 2008

\begin{tabular}{|c|c|c|c|c|c|c|c|}
\hline & \multicolumn{2}{|c|}{ Main and second jobs } & \multicolumn{2}{|c|}{ Main jobs } & \multicolumn{3}{|c|}{ Second jobs } \\
\hline & $\begin{array}{l}\text { Number } \\
(1,000 s)\end{array}$ & $\begin{array}{c}\text { as } \% \text { of UK } \\
\text { total }\end{array}$ & $\begin{array}{l}\text { Number } \\
(1,000 s)\end{array}$ & $\begin{array}{c}\text { as } \% \text { of UK } \\
\text { total }\end{array}$ & $\begin{array}{l}\text { Number } \\
(1,000 s)\end{array}$ & $\begin{array}{l}\text { as } \% \text { of UK } \\
\text { total }\end{array}$ & $\begin{array}{c}\text { as } \% \text { of } \\
\text { main and } \\
\text { second jobs }\end{array}$ \\
\hline Tourism industries & 2,546 & 8.4 & 2,362 & 8.1 & 184 & 16.6 & 7.2 \\
\hline Accommodation for visitors & 378 & 1.2 & 355 & 1.2 & 23 & 2.1 & 6.1 \\
\hline Food and beverage serving & 1,038 & 3.4 & 965 & 3.3 & 74 & 6.6 & 7.1 \\
\hline Passenger transport and travel & 519 & 1.7 & 504 & 1.7 & 15 & 1.3 & 2.8 \\
\hline Culture, sport, recreation and conferences & 610 & 2.0 & 538 & 1.8 & 73 & 6.6 & 11.9 \\
\hline Non-tourism industries & 27,832 & 91.6 & 26,908 & 91.9 & 924 & 83.4 & 3.3 \\
\hline All industries & 30,378 & 100.0 & 29,270 & 100.0 & 1,108 & 100.0 & 3.6 \\
\hline
\end{tabular}

Source: Annual Population Survey 2008

\section{Full-time and part-time jobs}

According to the APS, in 2008, around 38 per cent of main jobs in tourism industries were parttime, compared to just under a quarter in non-tourism industries. As Figure 2 indicates, part-time working was most common in food and beverage serving but was less prevalent in travel and transport industries. In total, 12.0 per cent of part-time main jobs in the UK were in tourism industries compared to less than 7 per cent of full-time main jobs. In fact, food and beverage serving was the industry of more than 6 per cent of all part-time main jobs (but only just over 2 per cent of full-time jobs).

The APS asks respondents who are working part-time in their main job to supply information about their reasons for working part-time. In non-tourism industries, the vast majority of respondents in 2008 classified themselves as not wanting a full-time job. As Figure 2 also illustrates, this is not the case in tourism industries where about half classified themselves in this way, just over a third were students and there was a greater proportion of people working part-time because they were unable to find a full-time job (13 per cent compared to almost 10 per cent in other industries).

In 2008 almost one in five of students working part-time were in food and beverage serving industries as were nearly one in ten of part-time workers unable to find a full-time job. These industries, however, only included 3 per cent of those working part-time because they did not want a full-time job. 


\section{Figure 2 Part-time employment in main jobs by reported reason, 2008}

Percentage of main jobs ${ }^{1}$

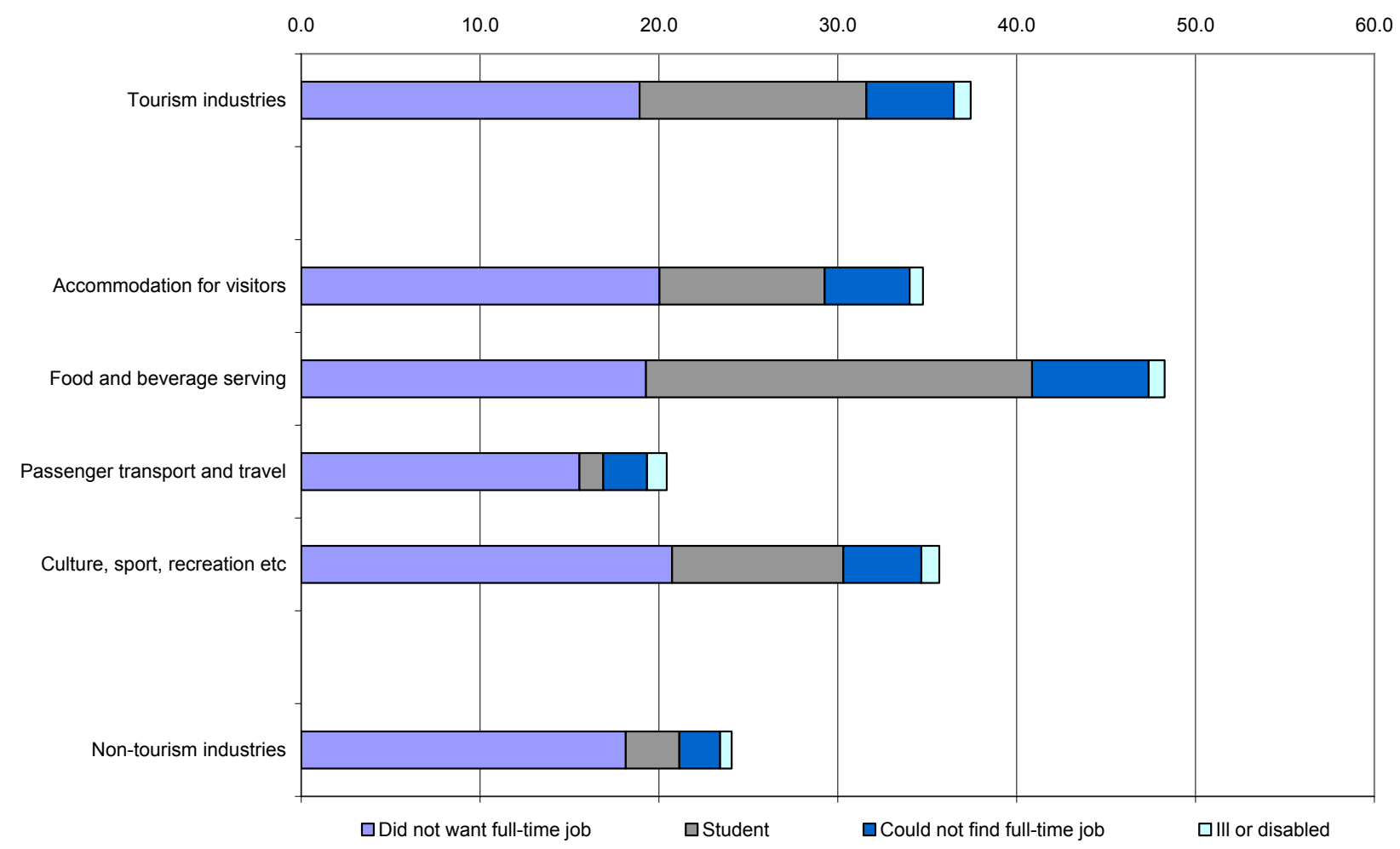

Source: Annual Population Survey 2008

Note

1. Proportions exclude part-time workers who gave no reason

\section{Self-employment}

In 2008, around 21 per cent of employment in main or second jobs in tourism industries was selfemployment, compared with 13 per cent in non-tourism industries. As Figure 3 indicates, selfemployment was particularly prevalent in transport and travel industries and in culture, sport and recreation. In total, almost 13 per cent of UK workers who were self-employed in their main or second job were in tourism industries but this was true of only 7.7 per cent of employees.

The category of 'other' in Figure 3 includes those with main jobs as unpaid family workers or that were part of Government schemes. Just over 100,000 workers in the UK classified themselves as the former in 2008 and about 11 per cent were in tourism industries, particularly those providing accommodation. Very few main jobs in Government schemes were in tourism (the exact estimate is not available due to the data being disclosive). 


\section{Figure $3 \quad$ Employment status in main and second jobs in 2008}

Percentages

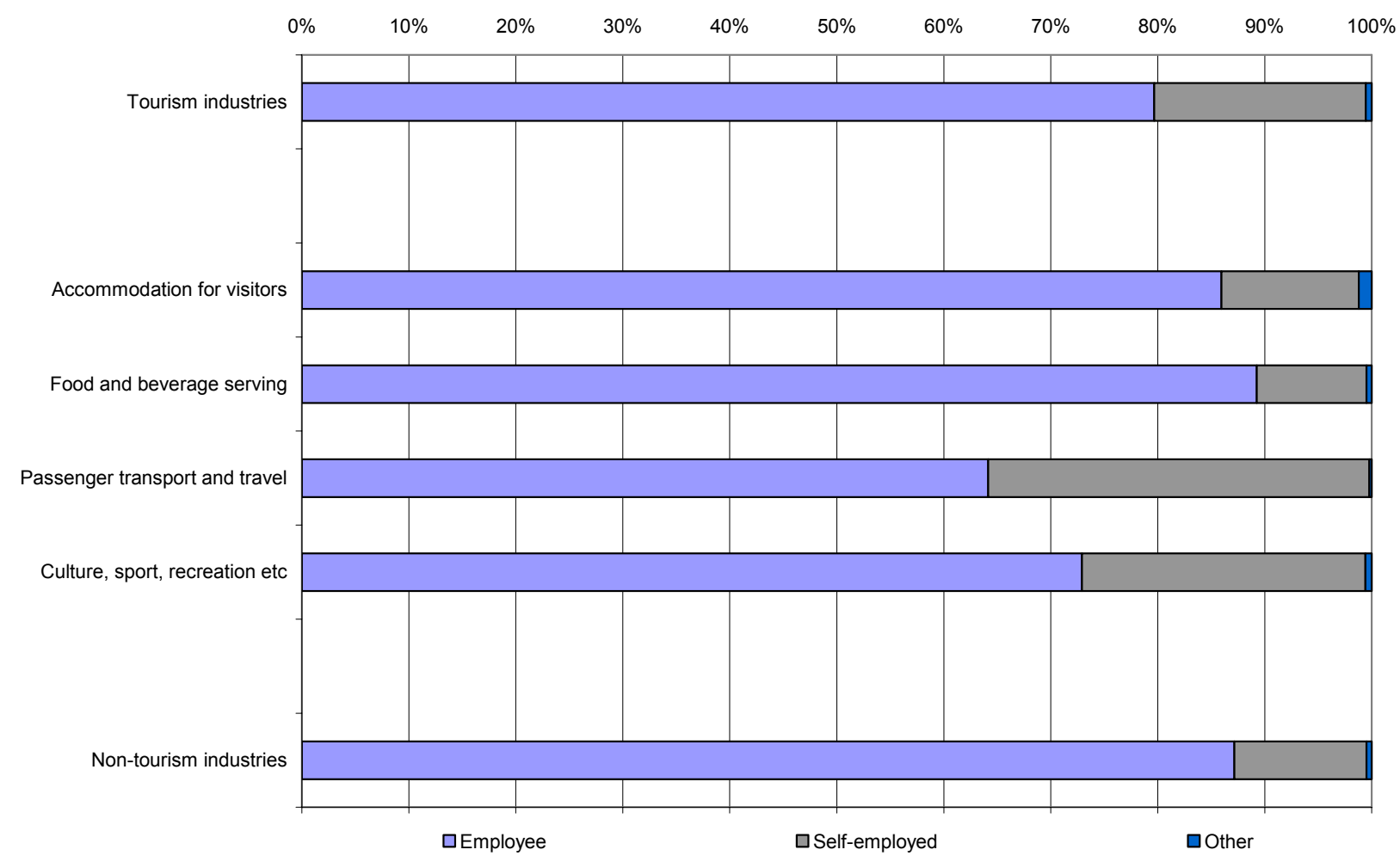

Source: Annual Population Survey 2008

\section{Temporary working}

The APS gives information about whether jobs are permanent or temporary in some way, including a breakdown of the latter into types of temporary working. In 2008, about 11 per cent of main and second job employment in tourism industries was temporary, compared with 6 per cent in nontourism industries. As Figure 4 indicates, the proportion of temporary jobs was highest in culture, sport and recreation.

Figure 4 also shows that the proportions of casual and seasonal work among tourism industries were much higher than in non-tourism industries where the type of temporary working was more likely to be fixed term or task (non-seasonal) work. In total, 38 per cent of seasonal work and 29 per cent of casual work in UK main and second jobs were within tourism industries in 2008. 


\section{Figure 4 Temporary working in main and second jobs in 2008}

Percentage of main and second jobs

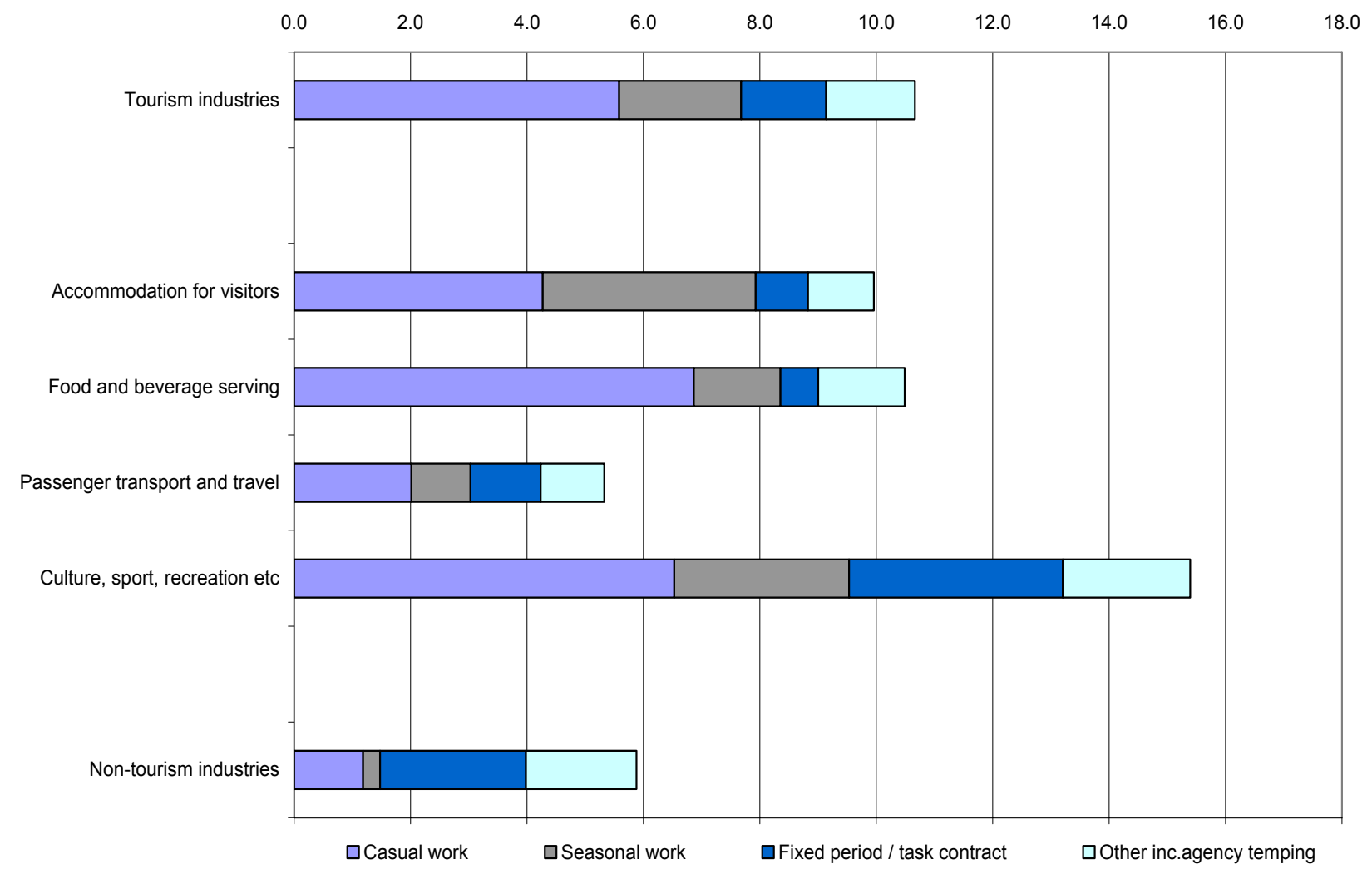

Source: Annual Population Survey 2008

\section{Public and private sector}

The APS includes information about whether the main job of a worker is reported to be in the public or private sector. In 2008, only 7 per cent of main job employment in tourism industries was reported to be in the public sector, compared to 26 per cent elsewhere. As Figure $\mathbf{5}$ indicates, culture, sport and recreation is the only group of tourism industries where public sector employment makes up more than 5 per cent of main job employment. In total, tourism industries are responsible for 9.8 per cent of all main jobs in the private sector but only 2.5 per cent of those in the public sector. 


\section{Figure 5 Private or public sector in main job (reported) in 2008}

Percentages

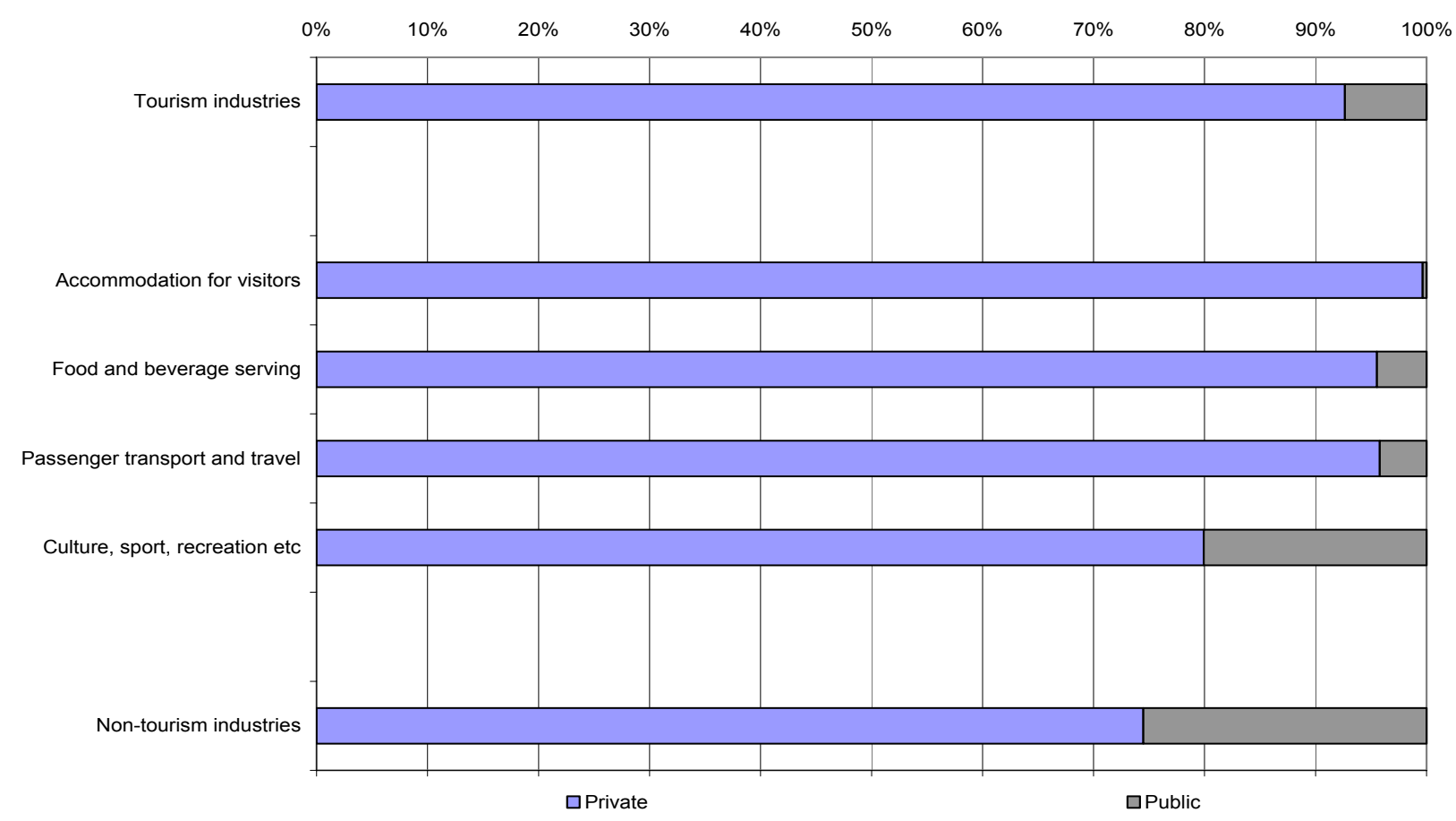

Source: Annual Population Survey 2008

\section{Characteristics of those with jobs in tourism industries}

\section{Age}

The 2008 APS indicates that the age profile of those employed in tourism is younger than those in other industries, as illustrated in Figure 6. More than a quarter of those in employment in main and second jobs in tourism industries were under 25 years old compared with about 13 per cent in other industries. The proportion of those aged 25 to 29 was also higher within tourism industries but the only other age group where this was the case was those aged 65 and over. 


\section{Figure 6 Proportion of workers by age group in main and second jobs in 2008: tourism and non-tourism industries}

Percentages

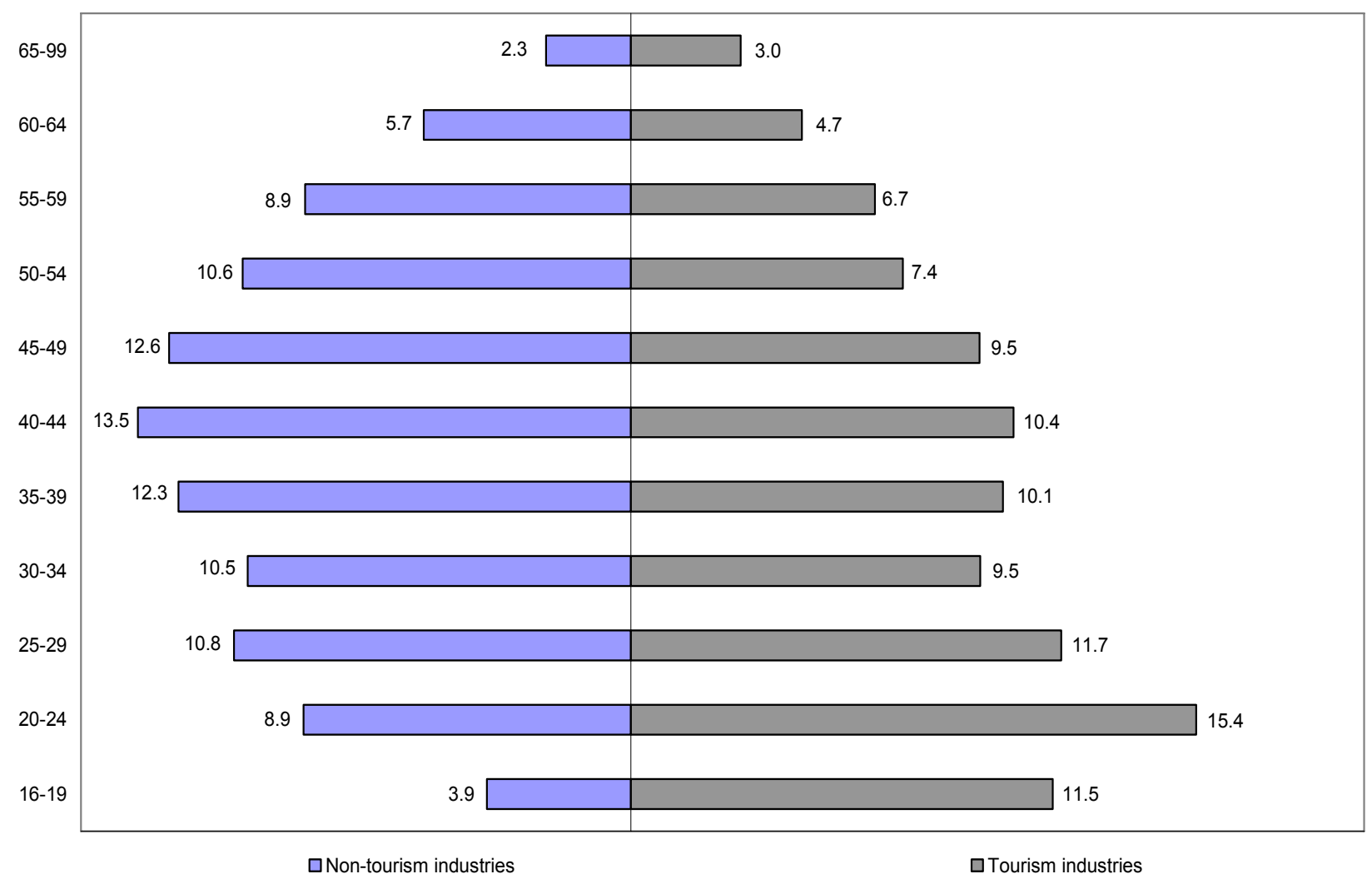

Source: Annual Population Survey 2008

The age profile of those employed in food and beverage serving is younger than that of other tourism industries, as Figure 7 indicates. Over half of those with main or second jobs in this industry are aged under 30. Accommodation for visitors and culture, sport and recreation have similar age profiles to that of tourism industries as a whole but the age breakdown of employment in passenger transport and travel is nearer to that in non-tourism industries. 


\section{Figure $7 \quad$ Proportion of workers in main and second jobs in 2008 by age group: comparisons between tourism industries}

Percentages

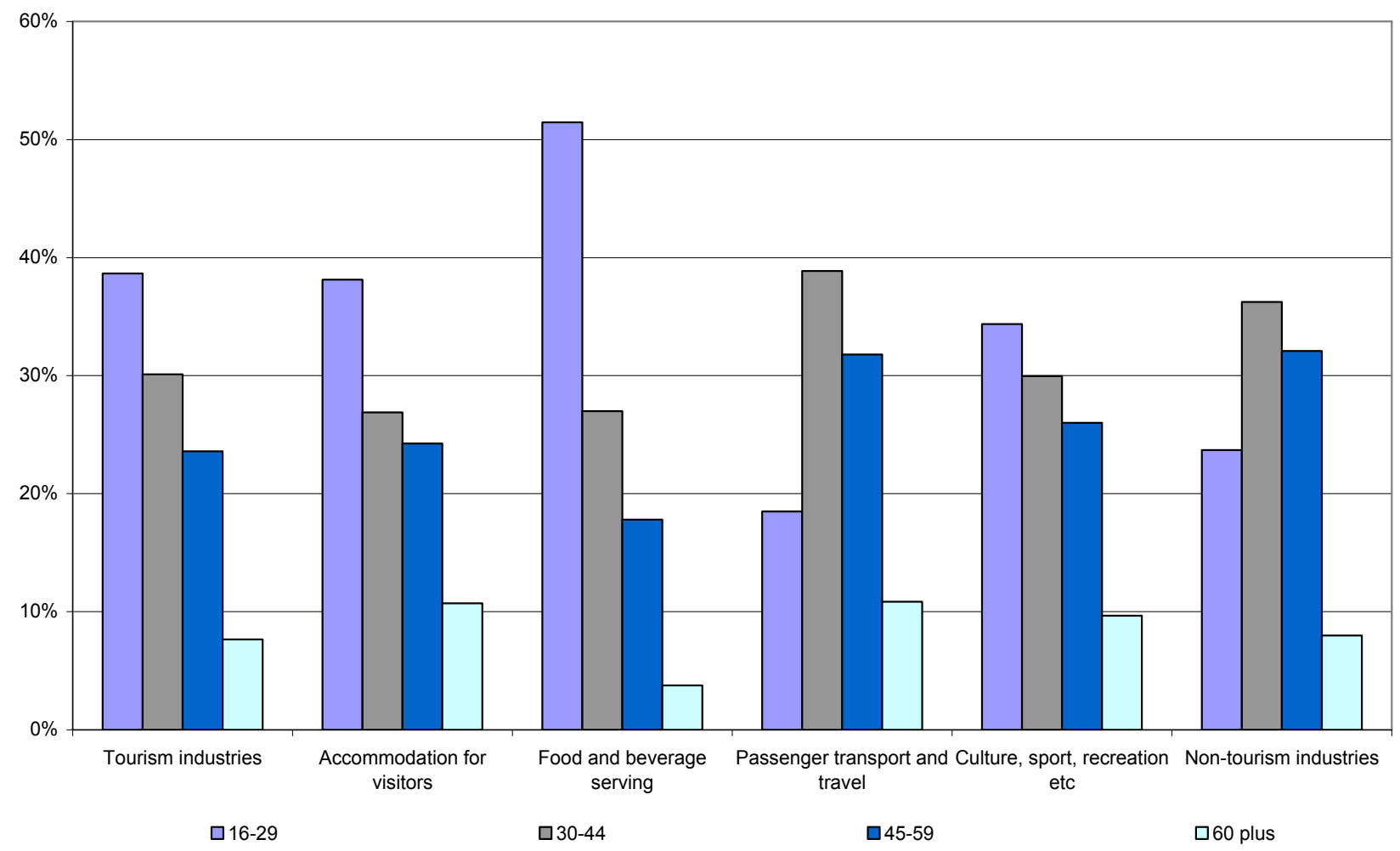

Source: Annual Population Survey 2008

\section{Gender}

The gender split of employment in main and second jobs in tourism industries in 2008 was similar to that in non-tourism industries, as Figure 8 illustrates. In both cases there were slightly more male workers than females but within tourism industries the proportions varied. Culture, sport and recreation industries had the same gender split as non-tourism industries but accommodation and food and beverage serving both had a majority of female workers. Passenger transport and travel had by far the highest proportion of male workers. 


\section{Figure $8 \quad$ Proportion of workers in main and second jobs by gender in 2008}

Percentages

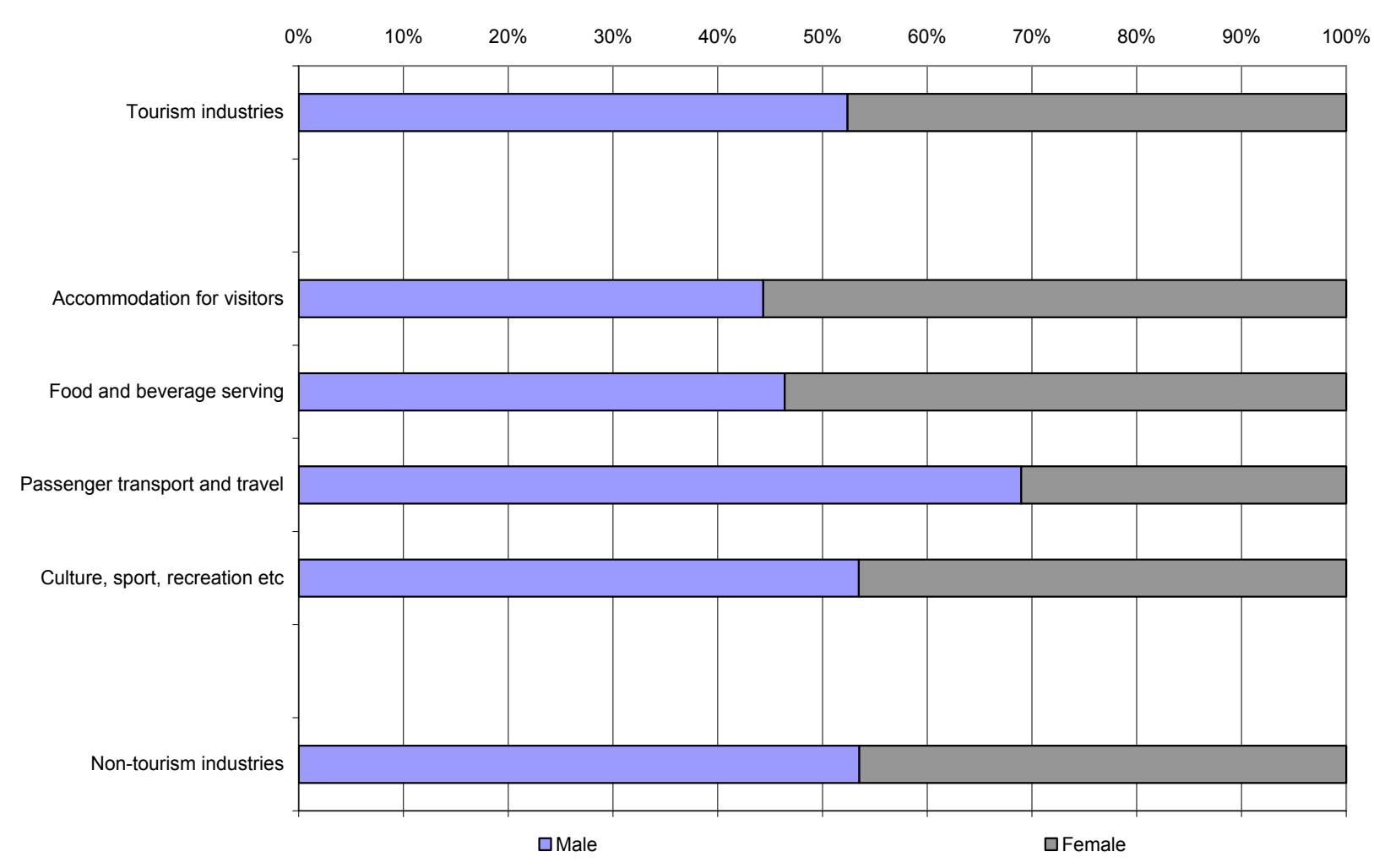

Source: Annual Population Survey 2008

\section{Nationality}

The APS indicates that almost 13 per cent of main and second jobs in tourism industries were held by workers with a non-UK nationality in 2008. This compares to around 7 per cent in other industries and means that 14 per cent of all main and second jobs held by non-UK workers were in tourism industries while this was true of only 8 per cent of those held by UK workers. As Figure 9 illustrates, the proportion of non-UK workers in the food and beverage serving and accommodation industries was more than twice that in other tourism industries.

Figure 9 also gives an indication of the nationalities of non-UK workers in tourism industries, particularly highlighting the food and beverage serving industry and the high proportions of workers from outside the EU and from the 12 accession countries (A12) that joined the EU in the $21^{\text {st }}$ Century. In 2008, tourism industries were home to 14 per cent of main and second jobs of workers in each of the three nationality groupings in Figure 9. 


\section{Figure $9 \quad$ Non-UK ${ }^{1}$ nationality in main and second jobs in 2008}

Percentage of main and second jobs

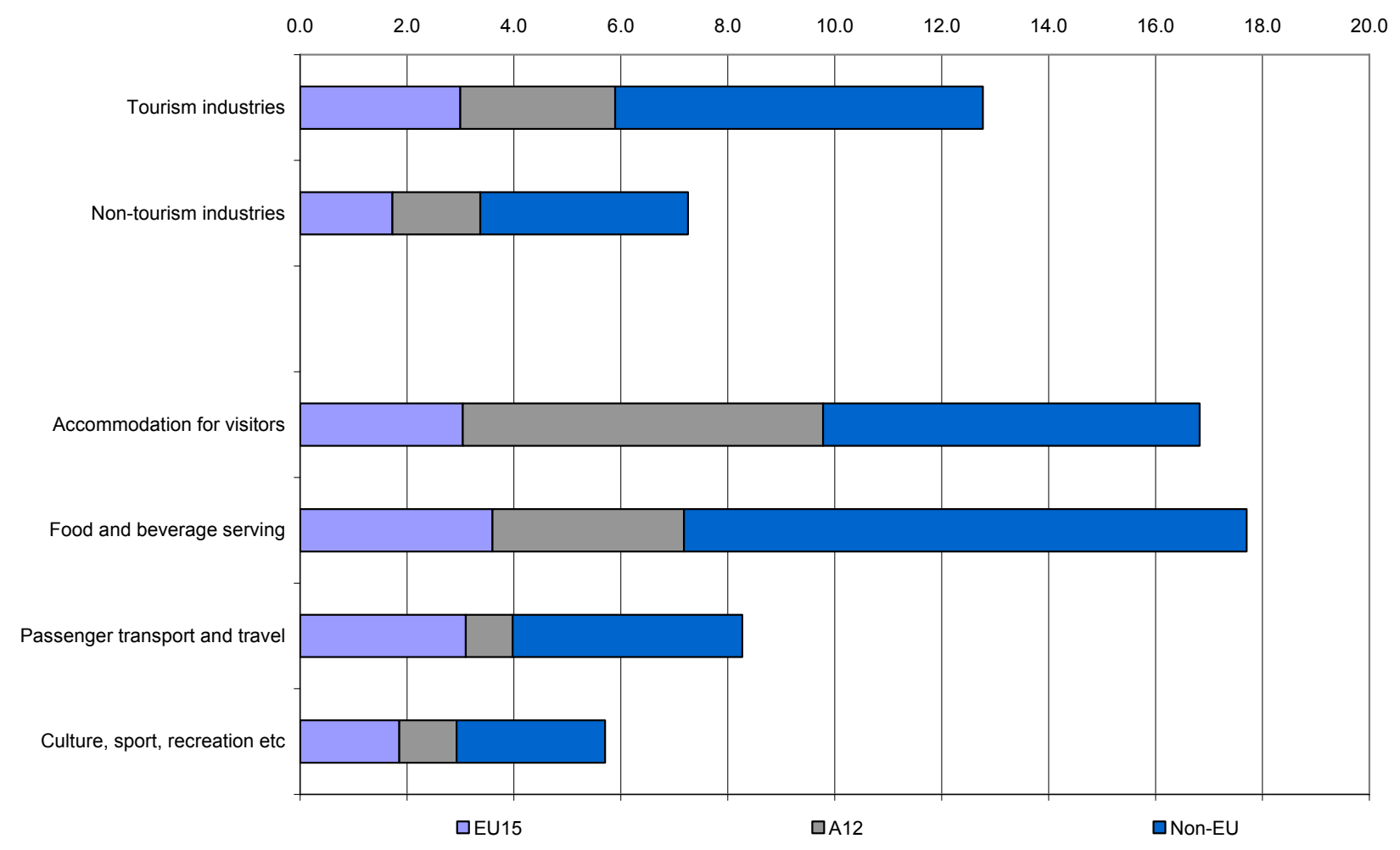

Source: Annual Population Survey 2008

Note

1. EU15 $=$ Nations in the EU prior to 2004, A12 = Nations that joined the EU in 2004 and 2007

\section{Ethnicity}

In 2008, around 14 per cent of main and second jobs in UK tourism industries were held by workers of a non-white ethnicity, according to the APS. This was a higher proportion than in nontourism industries where the figure was just over 8 per cent. As Figure 10 illustrates, the proportions of non-white workers were highest in the passenger transport and travel and food and beverage serving industries. In total, around 13 per cent of all main and second jobs in the UK held by workers of a non-white ethnicity were in tourism industries in 2008.

Figure 10 also gives information about how the proportions of main and second jobs in tourism industries are broken down into broad non-white ethnic groups. It highlights how workers of an Asian or Asian British ethnicity were prevalent in transport and travel industries and, to a lesser extent, food and beverage serving in 2008. 


\section{Figure 10 Non-white ethnicity in main and second jobs in 2008}

Percentage of main and second jobs

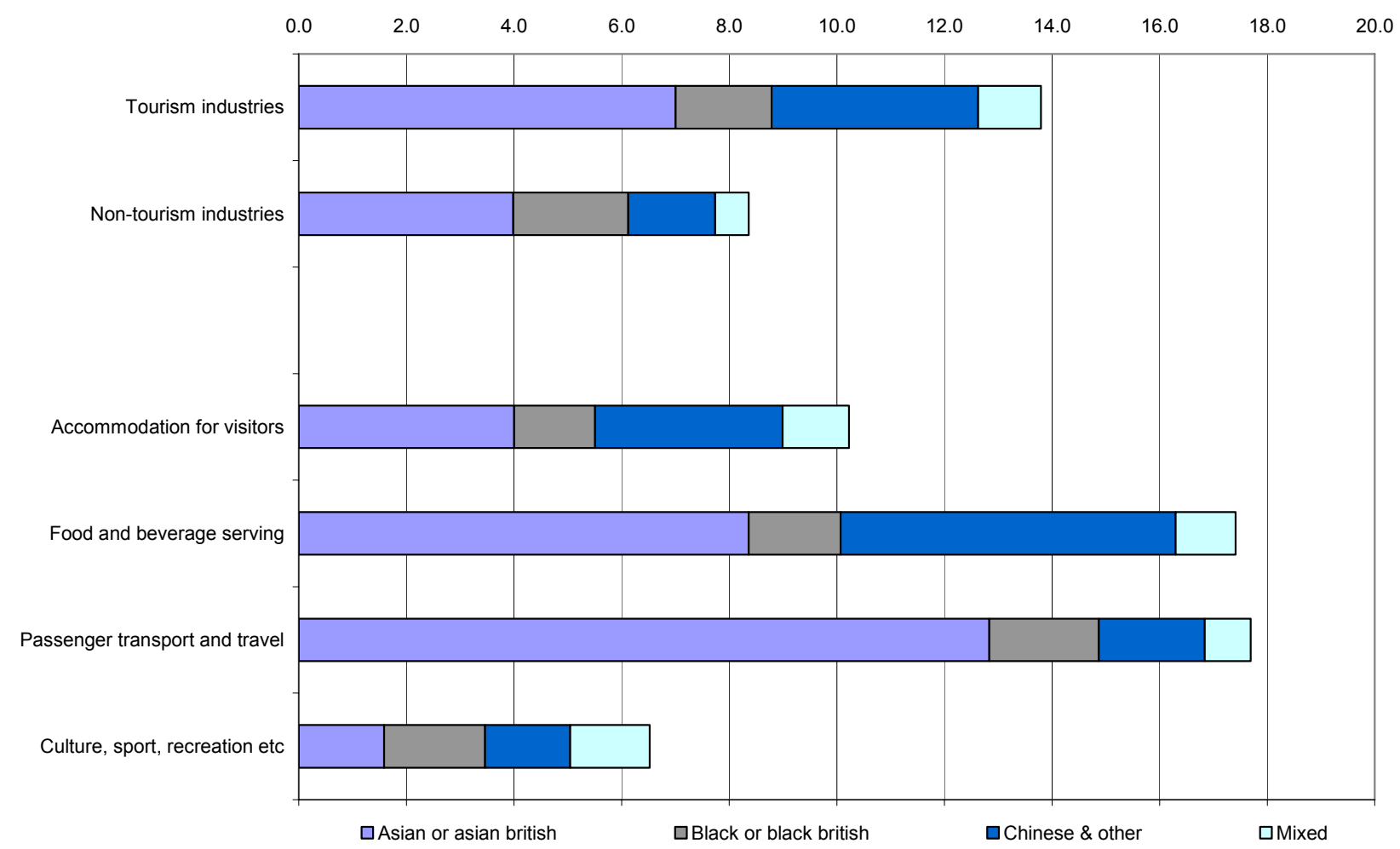

Source: Annual Population Survey 2008

\section{Qualifications}

The APS indicates that the qualification level of workers with main or second jobs in tourism industries in 2008 was, in general, lower than in other industries. As Figure 11 illustrates, around 16 per cent were qualified to degree level and above, compared to 25 per cent in non-tourism industries, while 47 per cent were qualified to GCE A Level and above, compared to 58 per cent elsewhere. About 12 per cent of workers in tourism industries in 2008 had no qualifications compared to 9 per cent in other industries.

As Figure 11 also shows, qualification levels of workers in cultural, sport and recreational industries were higher than in other tourism industries with 30 per cent qualified to degree level and above and only 8 per cent with no qualifications. On the other hand, the equivalent proportions among workers in the food and beverage serving industry were 9 per cent and 14 per cent. 


\section{Figure 11 Highest qualifications of workers in main and second jobs in 2008}

Percentage of main and second jobs ${ }^{1}$

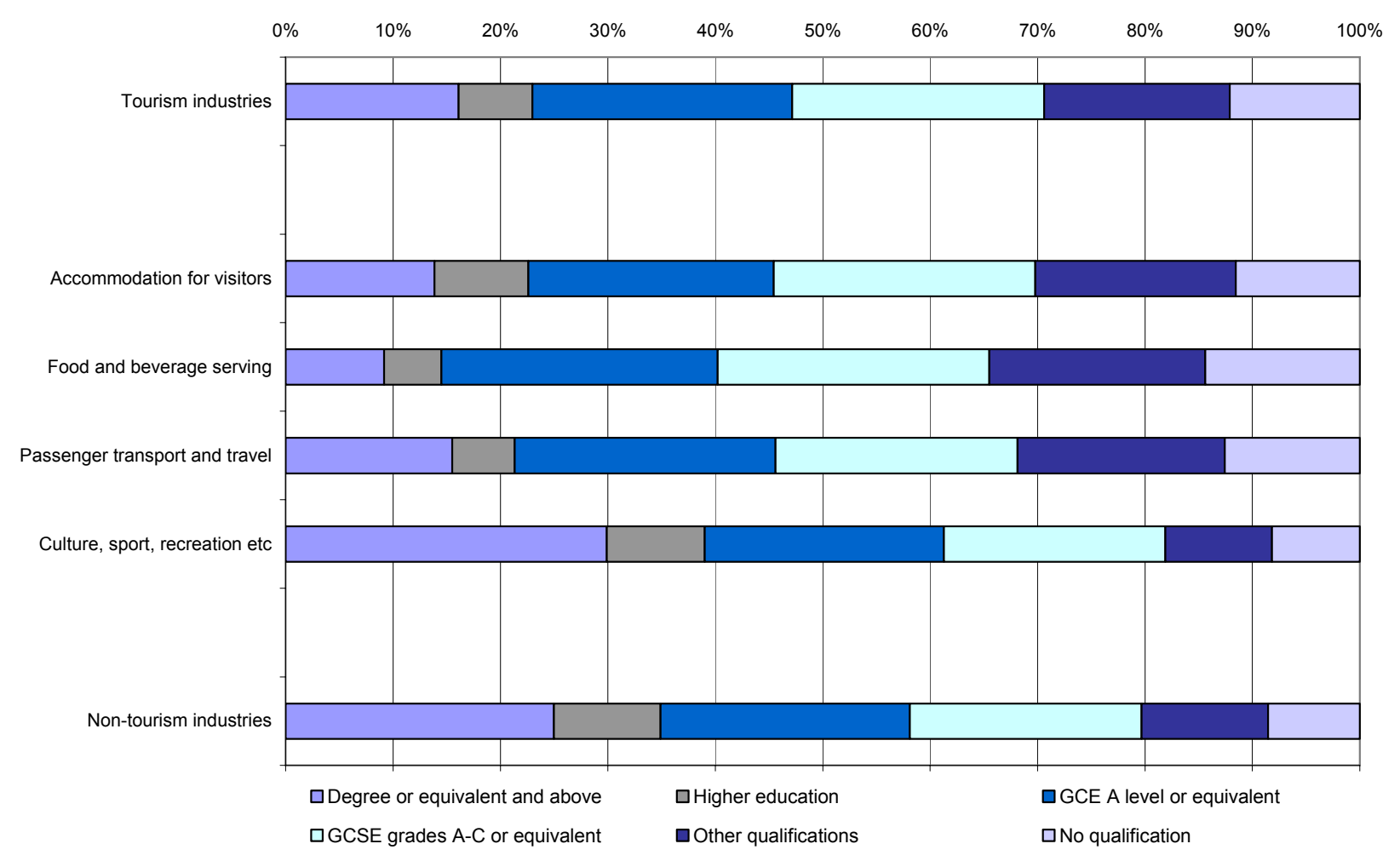

Source: Annual Population Survey 2008

Note

1. Proportions exclude 'don't know' responses

\section{The geography of employment in tourism industries}

\section{Regions}

The APS includes information about the location of workers' residences and of the workplace of their main and, if appropriate, second job. According to both residence and workplace based analyses, London had the highest proportion of workers in main and second jobs within tourism industries of the 12 UK NUTS 1 regions in 2008 while Northern Ireland had the lowest.

Figure 12 shows residence based data for all NUTS 1 areas in 2008 and shows that, outside of London, tourism industries were most important, in employment terms to workers living in Scotland. The shares of workers in the different tourism industries varied by region with, for example, employment in culture, sport and recreation being most prevalent among London residents while the percentage of employment in accommodation was largest in the South West and Scotland. Workplace based data would produce a similar chart at regional level but for sub- 
regions there are greater differences in the proportions as commuting has a greater effect. For this reason the NUTS 2 and 3 maps that follow are based on workplace data.

\section{Figure 12 Resident workers in main and second jobs in tourism industries in 2008}

Percentage of total in all industries

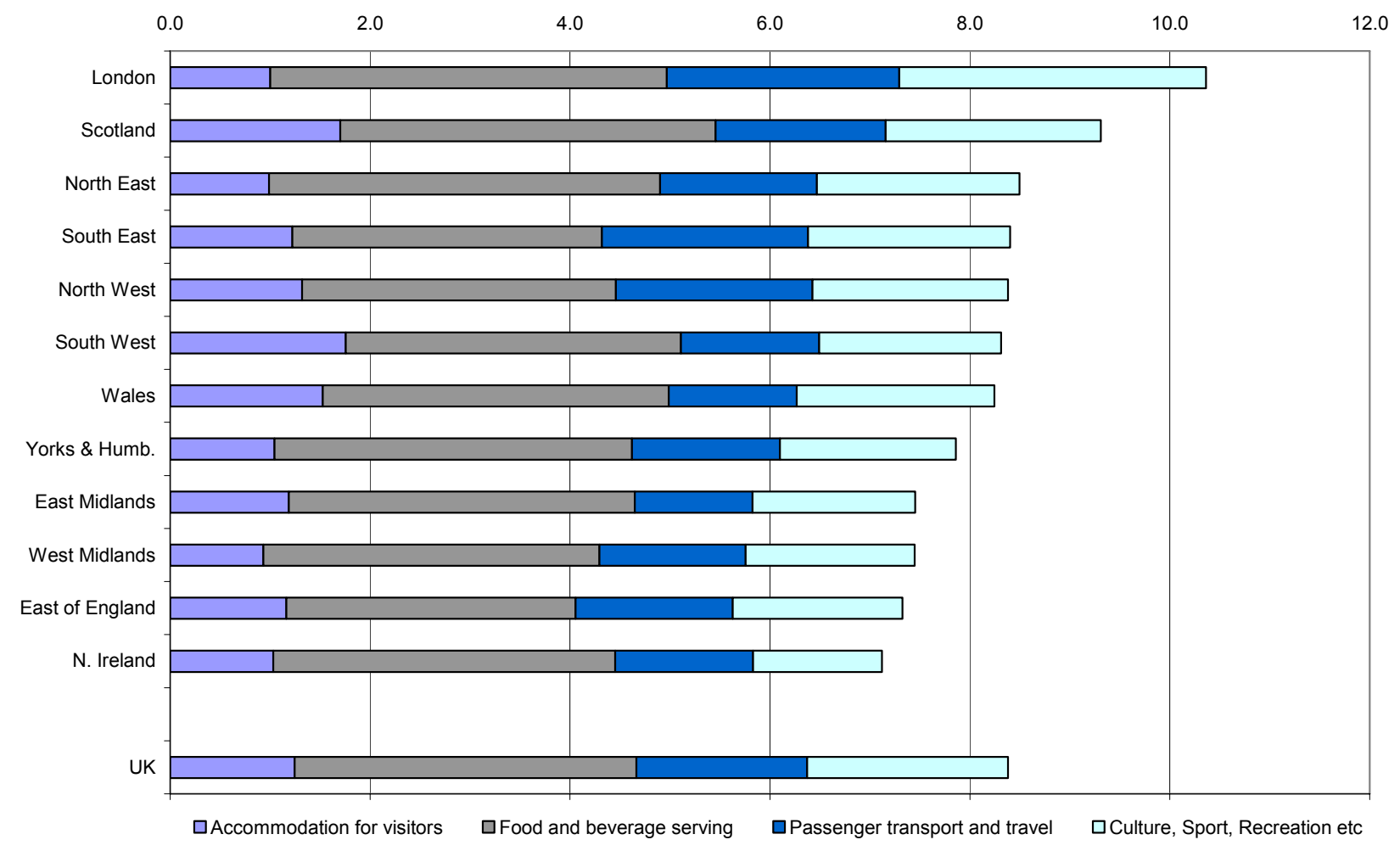

Source: Annual Population Survey 2008

\section{Rural / urban split}

Each residence in the APS in Great Britain is classified using an ONS rural or urban definition that describes the area the address is within. Figure 13 illustrates that the differences in proportion of employment in tourism between areas in 2008 related more to the sparseness or remoteness of the area than to the size of settlement. A greater proportion of workers resident in sparse or very remote areas were within tourism industries than in other areas in 2008 and workers in the accommodation industry were particularly common.

Although the overall proportions of employment in tourism within different types of settlement were similar in 2008, there were some differences between the tourism industries that were prevalent, with proportions of workers in food and beverage serving higher in more urban locations and the number of workers in the accommodation industry higher in more rural locations. 


\section{Figure 13 Resident workers in main and second jobs in tourism industries by rural/urban classification, 2008}

Percentage of the total in all industries

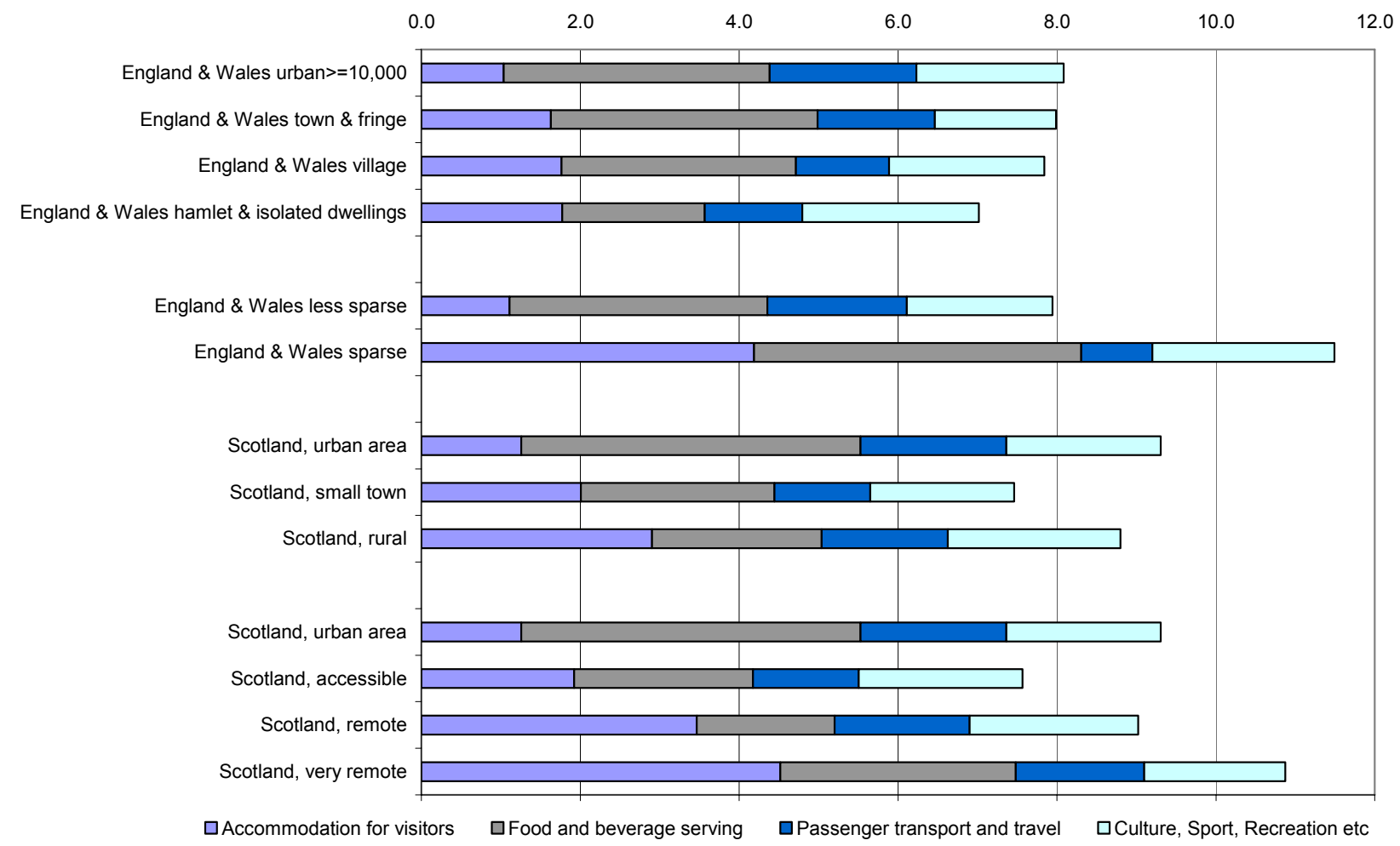

Source: Annual Population Survey 2008

\section{Sub-regional geographies}

The TIU has produced 2008 estimates of proportions of employment in tourism industries at subregional (NUTS 2) and local area (NUTS 3) level on a workplace basis. The estimates are aggregations of information from each APS respondent about the local authority within which they work in their main job and second job, where applicable. The paucity of observations within a number of NUTS 3 areas for the four broad tourism industries have meant that, for this geography, only the percentage of employment in all tourism industries has been mapped.

As Figure 14 illustrates, in 2008, the NUTS 3 areas with the highest proportions of workplace employment in tourism industries were generally those that had one or more of the following attributes:

- coastal resorts

- attractive scenery

- important airports

- other important transport facilities

- part of Central London 
The four NUTS 2 maps in Figure 15 indicate that the geographical patterns of employment in different tourism industries in 2008 differed quite considerably. For example, outer London had proportions of employment in passenger transport and travel, and in culture, sport and recreation that were among the highest in the UK but the percentage of employment in accommodation in the area was among the lowest.

Figure 14 Workplace-based employment in tourism industries by NUTS 3 area, 2008

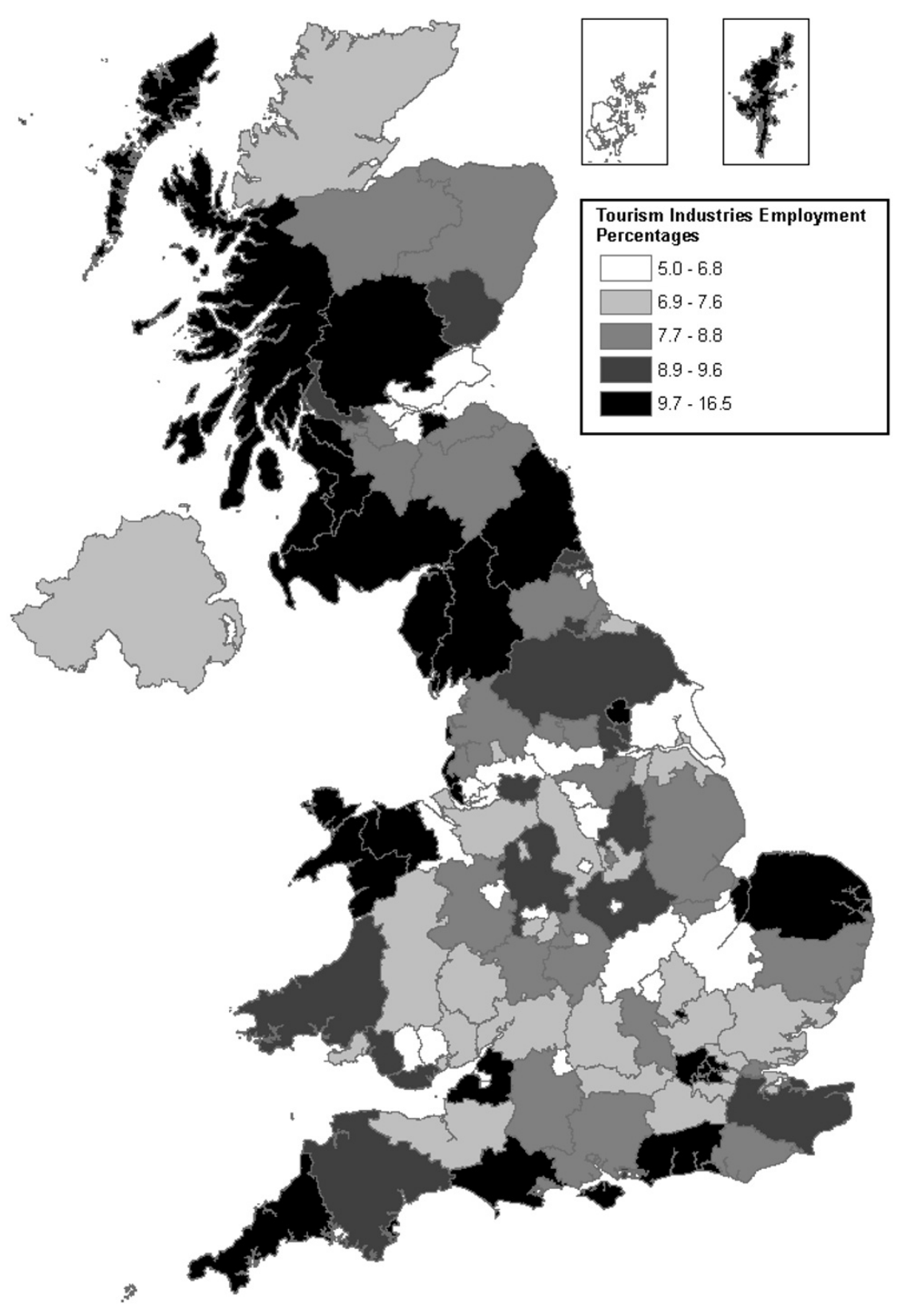


Figure 15 Workplace-based employment in tourism industries by NUTS 2 Area, 2008
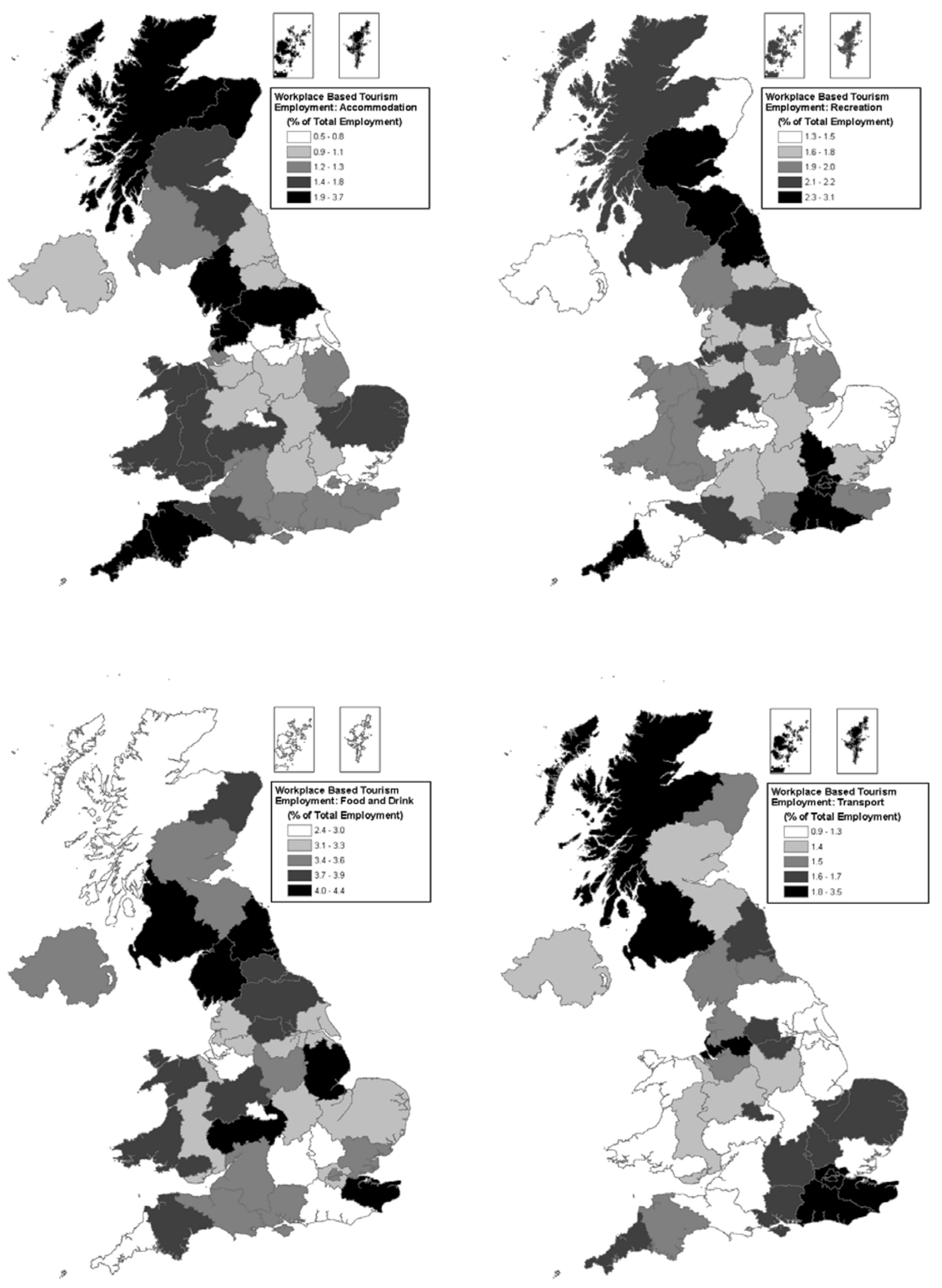


\section{Conclusion and future work}

This article illustrates that the internationally agreed definition of tourism industries includes several diverse industry groups and occupations. In general, tourism industries in the UK had a greater incidence of part-time employment, temporary employment and second jobs in 2008, but, within these industries, proportions of such types of employment varied considerably. Similarly, the percentages of workers with a main or second job in tourism industries who were under 30 years old, of a non-UK nationality, of non-white ethnicity or who had no qualifications were larger than those in non-tourism industries but there were distinct differences between the types of tourism industries.

In the future the TIU intends to revisit this analysis using data for other years to provide information about change over time in the employment patterns of UK tourism industries.

At a regional and sub-regional level the proportion of total employment in tourism industries in 2008 was highest in London and other areas that are traditionally tourism focused. However, more detailed geographical patterns of employment indicate that the type of industry that was most prevalent varied across such areas.

In early 2011, the TIU will add the regional and sub-regional data used for charts and maps in this article to the ONS website (to be accessed via www.statistics.gov.uk/tiu).

As mentioned at the start of the article, the TIU is considering whether an estimate of 'Tourism Direct Employment' could be included in the UK Tourism Satellite Account (TSA) for 2008 due to be published in 2011.

\section{Notes}

1. The TIU was set up in ONS in August 2008, with external funding. One of the Unit's aims is to make improvements to tourism statistics and it has a web page at: www.statistics.gov.uk/tiu

2. ONS (2010). UK Standard Industrial Classification of Economic Activities 2007 (version: January 2010). Available at: www.statistics.gov.uk/statbase/product.asp?vlnk=14012

3. Further information about the Annual Population Survey is available at: www.ons.gov.uk/aboutstatistics/user-guidance/lm-guide/sources/household/aps/index.html

4. Local Area Labour Market Data from the APS are available via: www.statistics.gov.uk/onlineproducts/lms_regional.asp and https://www.nomisweb.co.uk/

5. UK population by country of birth and nationality data from the APS are available via: www.statistics.gov.uk/statbase/Product.asp?vlnk=15147

6. More information about the VML is available at: www.ons.gov.uk/about/who-we-are/our-services/vml/index.html 
7. UNWTO, EUROSTAT, OECD (2008) International Recommendations on Tourism Statistics (IRTS, 2008), Madrid, Luxembourg, Paris. Available at:

http://unstats.un.org/unsd/tradeserv/tourism/Methodology.htm

8. ONS (2000) Standard Occupational Classification 2000. Available at: www.ons.gov.uk/aboutstatistics/classifications/archived/SOC2000/index.html

\section{Contact}

elmr@ons.gov.uk

\section{Reference}

Smith E, Webber D and White S (2010) 'The Supply Side of Tourism'. Available at: www.statistics.gov.uk/downloads/theme_transport/supplysidetourism.pdf

\section{Copyright Notice}

This work contains statistical data from ONS which is Crown copyright and reproduced with the permission of the controller of HMSO and Queen's Printer for Scotland. The use of the ONS statistical data in this work does not imply the endorsement of the ONS in relation to the interpretation or analysis of the statistical data. This work uses research datasets which may not exactly reproduce National Statistics aggregates.

Copyright of the statistical results may not be assigned, and publishers of this data must have or obtain a licence from HMSO. The ONS data in these results are covered by the terms of the standard HMSO "click-use" licence. 